\title{
A PRELIMINARY REPORT ON ANTIBIOTIC RESISTANT ESCHERICHIA COLI NON- O157 ISOLATED FROM CATTLE IN KADUNA STATE, NIGERIA
}

\author{
J. A. Musa ${ }^{1}$, H. M. Kazeem ${ }^{1}$, M. A. Raji ${ }^{1}$ and N. M. Useh ${ }^{1,2^{*}}$ \\ ${ }^{1}$ Department of Veterinary Pathology and Microbiology, Ahmadu Bello University, Zaria, Nigeria \\ ${ }^{2}$ Laboratory of Molecular Biology of Infectious Diseases, Department of Population Medicine and Diagnostic \\ Sciences, Cornell University, Ithaca, New York, United States of America
}

\begin{abstract}
A total of two hundred and forty (240) faecal samples were obtained from apparently healthy (233) and diarrhoeic (7) cattle in 8 randomly selected commercial farms in Kaduna State, Nigeria. Presumptive E. coli colonies from $76(31.2 \%)$ faecal samples were confirmed based on standard procedure. Characterization of isolates revealed three heterogeneous serogroups (O111, O118 and O126) from 6 apparently healthy cattle, while no E. coli serogroup was isolated from diarrhoeic cattle. Six (6) non-O157 serogroups obtained from cattle faeces were tested for antimicrobial susceptibility. The antimicrobial susceptibility test indicated that isolates from cattle faeces were $100 \%$ resistant to nitrofurantoin, amoxicillin and cefuroxime, and $100 \%$ sensitive to ciprofloxacin and ofloxacin. The study confirmed cattle as important source of antibiotic-resistant enterohaemorrhagic Escherichia coli in Kaduna state, Nigeria.
\end{abstract}

Key words: Antimicrobial sensitivity, Escherichia coli, cattle, Nigeria

\section{INTRODUCTION}

Antimicrobial sensitivities have been determined on Mueller-Hinton agar by disk diffusion method using certain antimicrobial agents for Gram negative bacteria, including Escherichia coli (Cheesbrough, 2000). The relatively high frequency of antimicrobial-resistant $E$. coli of cattle may be due to the use of antimicrobial drugs in cattle production (Schroeder et al., 2002). Bovine O118:H16 strain showed resistance to antimicrobial agents such as ampicillin and tetracycline. This indicates that drug resistance genes accumulated over time in O118: H16 strains of E. coli (Pestana de Castro et al., 2003). Cattle may thus be an important source of new emerging antibiotic-resistant E. coli strains of non-O157 serogroups (Blanco et al., 2000; Clarke, 2001). E. coli O111 are the most frequently implicated non-O157 strains causing gastroenteritis with haemolytic uraemic syndrome (HUS), particularly in the United States of America and Europe (Bettelheim, 2000; Pearce et al., 2006). Previous studies show that majority of $\mathrm{O} 111$ serogroups were recovered from individuals with haemorrhagic colitis (HC) and HUS (Nataro and Kaper, 1998) than from cattle (Bettelheim, 2003). Cattle and human O118 serogroups represent the same clones and are similar in virulence attributes and antimicrobial drug resistance, labeling them as possible zoonotic pathogens or threat to human beings (Wieler et al., 2000; Maidhoff et al., 2002).

E. coli $\mathrm{O} 126$ has been reportedly isolated from the faecal samples of human beings (Bettelheim, 2000). The serogroup O126 has not been implicated in cases of HUS (Buchanan and Doyle, 1997; Bettelheim, 2000). Some non-O157 serogroups were among the major EHEC implicated in an outbreak of diarrhoea, HC and HUS in human beings elsewhere (Bettelheim, 2003). In this study, we report for the first time, the sensitivity pattern of $E$. coli non-O157 isolated from cattle in Kaduna state, Nigeria to some antimicrobials.

\section{MATERIALS AND METHODS}

\section{Study design}

The study was designed as a cross-sectional (prevalence) study and sample size was determined using the method described by Mahajan (1997).

\footnotetext{
*Corresponding e-mail address: nicodemus.useh@fulbrightmail.org

Copyright (C 2012 Bangladesh Society for Veterinary Medicine
} 


\section{J. A. Musa and others}

\section{Study area}

The study area was Kaduna State, which is located between latitude $10^{\circ}$ and $11{ }^{\circ} \mathrm{N}$ and longitude $7{ }^{\circ}$ and $8{ }^{\circ} \mathrm{E}$, North-Western Nigeria (Figure 1).

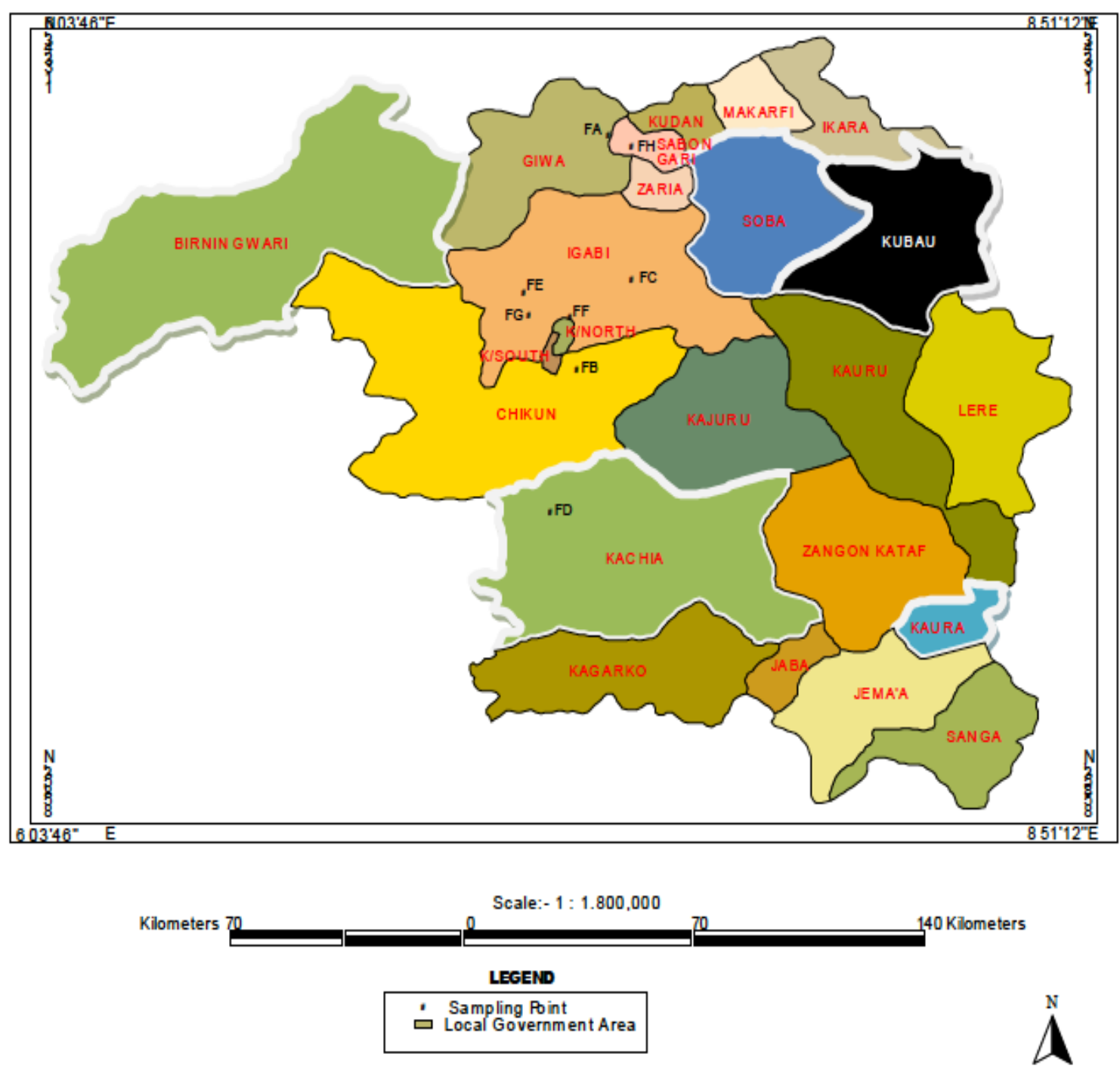

Fig.1: SAMPLING POINTS DISTRIBUTION IN KADUNA STATE 
Antibiotic resistant Escherichia coli non-O157 isolated from cattle

\section{Sample collection}

A total of two hundred and forty (240) faecal samples from apparently healthy (233) and diarrhoeic (7) cattle were collected from 8 randomly selected commercial farms in Kaduna state, Nigeria using stratified sampling technique (Field and Graham, 2003). The farms were designated as farms A (FA), B (FB), C (FC), D (FD), E (FE), F (FF), G (FG) and $\mathrm{H}(\mathrm{FH})$ located in five different local government areas of Kaduna State, Nigeria (Fig. 1). Faecal material (1-2 g) was aseptically collected from the rectum of each animal using clean disposable hand gloves. The samples were placed in separate sterile bottles containing 8-9 mL of tryptone soya broth (TSB), kept in a cold box at $4{ }^{\circ} \mathrm{C}$ and then transported to the Bacteriology Laboratory, Department of Veterinary Pathology and Microbiology, Faculty of Veterinary Medicine, Ahmadu Bello University, Zaria, Nigeria where they were processed immediately.

\section{Isolation and identification of suspected colonies}

Bacterial isolation, identification and biochemical tests were carried out using standard procedures described elsewhere (Cheesbrough, 2000).

\section{Biochemical characterization}

Colonies growing on EMB agar plates suspected to be $E$. coli were subjected to biochemical tests (indole, methyl red, Voges Proskauer, citrate (IMViC), motility and triple sugar iron, TSI) (Cheesbrough, 2000).

\section{Identification of somatic $O$ isolates}

The confirmed E. coli isolates were sub-cultured onto nutrient agar slants and stored at $4{ }^{\circ} \mathrm{C}$ for serogrouping (Blanco et al., 2006). Determination of somatic O antigens for EHEC O111, O118 and O126 was performed using specific antisera (SIFIN Berlin Germany) (Blanco, 2006).

\section{Sensitivity to antimicrobials}

The sensitivity pattern of the isolates to antimicrobials was determined on nutrient agar (NA) by disk diffusion method (Sozmen et al., 2011). These include nitrofurantoin (N, $100 \mu \mathrm{g}$ ), ciprofloxacin (Cip, $5 \mu \mathrm{g}$ ), tetracycline (Te, $50 \mu \mathrm{g}$ ), norfloxacin (nobactin- NB, $10 \mu \mathrm{g}$ ), amoxicillin (AX, $20 \mu \mathrm{g}$ ), ofloxacin (OF, $5 \mu \mathrm{g}$ ), chloramphenicol $(\mathrm{C}, 10 \mu \mathrm{g})$, cefuroxime (zinnat- $\mathrm{CF}, 30 \mu \mathrm{g}$ ), ampicillin (AM, $10 \mu \mathrm{g})$ and gentamicin (GN, $10 \mu \mathrm{g})$ (Poly-Test Med. Laboratories ${ }^{\circledR}$, Pune, India). The non-O157 positive E. coli isolates from commercial cattle farms were inoculated onto NA plates and the antimicrobial disks were placed on the plates using sterile forceps followed by incubation at $37^{\circ} \mathrm{C}$ for $18-24 \mathrm{~h}$.

\section{Statistical analysis}

The results were analyzed using chi-square two by two contingency table with statistical package for social sciences (SPSS) (Petrie and Watson, 1999) 14.0 version and Microsoft Excel version 2007.

\section{RESULTS}

Spatial distribution of enterohaemorrhagic $E$. coli

The specific prevalence of the farms investigated ranged between $0.0 \%$ (FA, FB, FC, FD and FG) and $10.0 \%$ (FF). A total of $6(2.5 \%)$ E. coli serogroups from apparently healthy cattle were found, of which $1(3.0 \%)$ isolated from $\mathrm{FE}$ and $\mathrm{FH}$ was $\mathrm{O} 111,1$ (4.4 \%) from FF was O118, 1 (3.0 \%) from $\mathrm{FH}$ and $2(8.7 \%)$ from FF were $\mathrm{O} 126$ serogroups respectively. E. coli isolates $\mathrm{O} 126$ occurred more frequently, followed by O111 and O118. Majority of the cattle farms had no E. coli serogroups. The P-value was statistically significant $(\mathrm{P}<0.05)$ (Table 1). 


\section{J. A. Musa and others}

Table 1. Specific prevalence of $E$. coli serogroups in commercial cattle farms in Kaduna State, Nigeria

\begin{tabular}{|ccccc|}
\hline Farm & Specific prevalence (\%) & \multicolumn{3}{c|}{ Positive E. coli serogroup (\%) } \\
\hline & & O111 & O118 & O126 \\
A & 0.0 & $0(0.0)$ & $0(0.0)$ & $0(0.0)$ \\
B & 0.0 & $0(0.0)$ & $0(0.0)$ & $0(0.0)$ \\
C & 0.0 & $0(0.0)$ & $0(0.0)$ & $0(0.0)$ \\
D & 0.0 & $0(0.0)$ & $0(0.0)$ & $0(0.0)$ \\
E & 3.3 & $1(3.0)$ & $0(0.0)$ & $0(0.0)$ \\
F & 10.0 & $0(0.0)$ & $1(4.4)$ & $2(8.7)$ \\
G & 0.0 & $0(0.0)$ & $0(0.0)$ & $0(0.0)$ \\
H & 6.7 & $1(3.0)$ & $0(0.0)$ & $1(3.0)$ \\
\hline Total & 2.5 & $3(0.8)$ & $1(0.4)$ & $3(1.3)$ \\
\hline
\end{tabular}

$\chi^{2}=0.04, \mathrm{P}(<0.05)$

\section{Sensitivity pattern of $E$. coli isolates to antimicrobials}

All 6 isolates tested were resistant to nitrofurantoin, amoxicillin and cefuroxime or zinnat and sensitive to ofloxacin and ciprofloxacin (Table 2). Resistance to chloramphenicol (83.3\%), ampicillin (66.7 \%), norfloxacin $(33.3 \%)$, gentamicin $(33.3 \%)$ and tetracycline $(16.7 \%)$ were also observed.

Table 2. Antimicrobial sensitivity pattern of E. coli non-O157 isolated from commercial cattle farms in Kaduna State, Nigeria

\begin{tabular}{|ccccccccccc|}
\hline Isolate no & & \multicolumn{10}{c|}{ Antimicrobial agent } \\
\hline & $\mathrm{N}$ & $\mathrm{CIP}$ & $\mathrm{TE}$ & $\mathrm{NB}$ & $\mathrm{AX}$ & $\mathrm{OF}$ & $\mathrm{C}$ & $\mathrm{CF}$ & $\mathrm{AM}$ & $\mathrm{GN}$ \\
E 3 & $\mathrm{R}$ & $\mathrm{S}$ & $\mathrm{S}$ & $\mathrm{S}$ & $\mathrm{R}$ & $\mathrm{S}$ & $\mathrm{R}$ & $\mathrm{R}$ & $\mathrm{R}$ & $\mathrm{S}$ \\
$\mathrm{F} \mathrm{5}$ & $\mathrm{R}$ & $\mathrm{S}$ & $\mathrm{S}$ & $\mathrm{R}$ & $\mathrm{R}$ & $\mathrm{S}$ & $\mathrm{R}$ & $\mathrm{R}$ & $\mathrm{R}$ & $\mathrm{S}$ \\
$\mathrm{F} \mathrm{14}$ & $\mathrm{R}$ & $\mathrm{S}$ & $\mathrm{S}$ & $\mathrm{S}$ & $\mathrm{R}$ & $\mathrm{S}$ & $\mathrm{R}$ & $\mathrm{R}$ & $\mathrm{R}$ & $\mathrm{S}$ \\
$\mathrm{F} \mathrm{18}$ & $\mathrm{R}$ & $\mathrm{S}$ & $\mathrm{R}$ & $\mathrm{S}$ & $\mathrm{R}$ & $\mathrm{S}$ & $\mathrm{R}$ & $\mathrm{R}$ & $\mathrm{S}$ & $\mathrm{S}$ \\
$\mathrm{H} \mathrm{10}$ & $\mathrm{R}$ & $\mathrm{S}$ & $\mathrm{S}$ & $\mathrm{R}$ & $\mathrm{R}$ & $\mathrm{S}$ & $\mathrm{R}$ & $\mathrm{R}$ & $\mathrm{R}$ & $\mathrm{R}$ \\
H 25 & $\mathrm{R}$ & $\mathrm{S}$ & $\mathrm{S}$ & $\mathrm{S}$ & $\mathrm{R}$ & $\mathrm{S}$ & $\mathrm{S}$ & $\mathrm{R}$ & $\mathrm{S}$ & $\mathrm{R}$ \\
\hline
\end{tabular}

$\mathrm{S}=$ Sensitive $(17-21 \mathrm{~mm}) \mathrm{R}=$ Resistant $(10-15 \mathrm{~mm}) \mathrm{N}=$ Nitrofurantoin $\mathrm{CIP}=$ Ciprofloxacin $\mathrm{TE}=$ Tetracycline $\mathrm{NB}=$ Norfloxacin (nobactin) $\mathrm{AX}=$ Amoxicillin $\mathrm{OF}=$ Ofloxacin $\mathrm{C}=$ Chloramphenicol $\mathrm{CF}=$ Cefuroxime (zinnat) $\mathrm{AM}=\mathrm{Ampicillin}$ $\mathrm{GN}=$ Gentamicin

\section{DISCUSSION}

The isolates from cattle farms investigated in this study were $100 \%$ resistant to nitrofurantoin, amoxicillin and cefuroxime. There are growing concerns by consumers and health officials regarding antibiotic resistance of food borne pathogens that may be associated with the practice of adding growth promoting antibiotics to animal feeds. This suggests that antimicrobial resistance is widespread among E. coli O111, O118 and O126 inhabiting cattle in commercial farms. Thus, cattle could be an important source of new emerging zoonotic antibiotic-resistant $E$. coli that may present a risk of spreading antibiotic resistance to human beings in Kaduna state, Nigeria. This is because isolates of $E$. coli have been implicated in human disease, leading to severe outbreaks, affecting a good number of populations. An example was that of E. coli O111 in America as reported by Belnap and O'Donnell (1955). Our findings are consistent with the works of Schröder et al. (2002) and Pestana de Castro et al. (2003), who reported resistance among E. coli $\mathrm{O} 111$ and $\mathrm{O} 118$ isolates that showed multi-resistance to about 8 different antimicrobial drugs, predominated by E. coli $\mathrm{O} 118$ strains. Thus, it may be suggestive that drug resistance genes may have accumulated over time in O111, O118 and could possibly occur in other non-O157 serogroups. 
This is the first report on E. coli non-O157 resistance in Kaduna state, Nigeria and therefore, there is no knowledge about the possible effect of drug resistant E. coli serotypes on the human populations in the study area. It is concluded that research should be carried out to document the presence and role of antimicrobial resistance genes in animal and human populations in the study area.

\section{ACKNOWLEDGEMENTS}

Professor RS Chauhan, Director, Institute of Biotechnology, GB Pant University of Agriculture and Technology, Patwadangar, Nainital, India provided a facility which was used to process the data generated from the experiment via a CV Raman fellowship to NM Useh for which the authors are most grateful. A United States Senior Fulbright research award to NM Useh at Cornell University, Ithaca, New York where the manuscript was prepared is also gratefully acknowledged. The authors declare no conflict of interest.

\section{REFERENCES}

1. Belnap W D and O'Donnell J J (1955). Epidemic gastroenteritis due to Escherichia coli O-111. In: Bettelheim, K.A. Supplement. Non-O157 verotoxin-producing Escherichia coli: A problem, paradox, and paradigm. Experimental Biology and Medicine 228: 333-344.

2. Bettelheim K A (2000). Role of non-O157 verocytotoxin-producing Escherichia coli (VTEC). Journal of Applied Microbiology 88: 38-50.

3. Bettelheim K A (2003). Non-O157 verotoxin-producing Escherichia coli: A problem, paradox, and paradigm. Experimental Biology and Medicine 228, 333-344.

4. Blanco M, Blanco J E, Mora A, González E A and Blanco J (2000). Serotypes and virulence genes of verocytotoxigenic E. coli (VTEC) isolated from cattle in Spain. In: Verocytotoxigenic E. coli in Europe, 3. Pathogenicity and virulence of verocytotoxigenic E. coli. G. Duffy, D. Garvey, P. Coia, J. Wasteson, Y. and McDowell D. A. (eds). Teagasc, The National Food Centre, Dublin. pp. 183.

5. Blanco J A (2006). A manual: kit for E. coli serotyping, including O2, O26, O78, O86 and O141 sera. Laboratorio de Referencia de E. coli (LREC), Espana, pp. 1-7.

6. Blanco M J, Blanco E, Bahbi C, Mora A, Alonso M P, Varela G, Gadea M P, Schelotto F, Gonzalez E A and Blanco J (2006). Typing of intimin (eae) genes from enteropathogenic Escherichia coli (EPEC) isolated from children with diarrhea in Montevideo, Uruguay: Identification of two novel intimin variants $(\mu \mathrm{B}$ and $\S \mathrm{R} / \beta 2 \mathrm{~B})$. Journal of Medical Microbiology 55: 1165-1174.

7. Buchanan R L and Doyle M P (1997). Food borne disease significance of Escherichia coli O157:H7 and other enterohaemorrhagic E. coli. Food Technology 51: 69-76.

8. Cheesbrough M. (2000). District laboratory practice in tropical countries. Lower price editions, part 2, Cambridge University Press, pp 381-407.

9. Clarke S C (2001). Diarrhoeagenic Escherichia coli-an emerging problem? Diagnostic Microbiology and Infectious Diseases 41: 93-98.

10. Maidhof H, Guerra B, Abbas S, Elsheikha H M, Whittam T S and Beutin L A (2002). Multi resistant clone of shiga toxin-producing Escherichia coli O118:[H16] is spread in cattle and humans over different European countries. Applied Environmental Microbiology 68: 5834-42.

11. Mahajan B K (1997). Methods in Biostatistics for Medical Students and Research workers. $6^{\text {th }} \mathrm{Ed}$, Jaypee brothers Medical Publishers Ltd, India. pp. 88-94.

12. Nataro J P and Kaper J B (1998). Diarrhoeagenic Escherichia coli. Clinical Microbiology Reviews 11: 142-201.

13. Pearce M C, Evans J, McKendrick I J, Smith A W, Knight H I, Mellor D J, Woolhouse M E J, Gunn G J and Low J C (2006). Prevalence and virulence factors of Escherichia coli serogroups O26, O103, O111, and O145 shed by cattle in Scotland. Applied Environmental Microbiology 72: 653659.

14. Pestana de Castro A F, Guerra B, Leomil L, Aidar-Ugrinovitch L and L Beutin, (2003): Multidrugresistant shiga toxin-producing Escherichia coli O118:H16 in Latin America. Emerging Infectious Diseases 9: 1027-1028. 


\section{J. A. Musa and others}

15. Petrie A and Watson P (1999). Statistics for Veterinary and Animal Science. Blackwell Science Ltd. pp. 101-109.

16. Schröder C M, Meng J, Zhao S, DebRoy C, Torcolini J, Zhao C, McDermott P F, Wagner D D, Walker R D and White D G (2002). Antimicrobial resistance of Escherichia coli O26, O103, O111, O128, and O145 from animals and humans. Emerging Infectious Diseases 8: 1409-1413.

17. Sozmen F, Uysal B, Oksal B S, Kose E O and Deniz I G (2011). Chemical composition and antimicrobial activity of Organum saccatun P.H. Davis essential oil obtained by solvent-free microwave extraction: comparison with hydrodistillation. Journal of Association of Analalytical Chemistry 94: 243-250.

18. Wieler L H, Busse B, Steinkuac H, Bentin L, Weber A, Karch H and Baljer G (2000). Enterohaemorrhagic Escherichia coli (EHEC) Strains of serogroup O118 display three distinctive clonal groups of EHEC pathogens. Journal of Clinical Microbiology 38: 2162 -2169. 